\title{
As reinvenções da Semiótica: entrevista com lone Bentz
}

\section{André Corrêa da Silva de Araujo}

Doutorando, Universidade Federal do Rio Grande do Sul, Porto Alegre, RS, Brasil andrecsaraujo@gmail.com

\section{Luis Felipe Silveira de Abreu}

Doutorando, Universidade Federal do Rio Grande do Sul, Porto Alegre, RS, Brasil paraluisabreu@gmail.com

\section{Sinara Regina Sandri}

Doutoranda, Universidade Federal do Rio Grande do Sul, Porto Alegre, RS, Brasil sinara.sandri@gmail.com

\section{Resumo}

Com mestrado em Linguística em 1974, na Pontifícia Universidade Católica do Rio Grande do Sul, e doutorado em 1980, na Universidade de São Paulo, a formação da professora e pesquisadora lone Maria Ghislene Bentz está ligada à chegada dos estudos linguísticos e semióticos ao Brasil, e ao seu posterior desenvolvimento como um campo de pesquisa fértil aos problemas da comunicação e da cultura. Professora aposentada pela Universidade Federal do Rio Grande do Sul, com passagem pelo Programa de Pós-Graduação em Ciências da Comunicação da Universidade do Vale do Rio dos Sinos, hoje, ela atua como professora e pesquisadora junto à Pós-Graduação em Design da mesma universidade. Nesta entrevista, a pesquisadora discute as particularidades da trajetória da Semiótica como campo de investigação no país, destacando não só suas potências enquanto instrumento epistemológico e heurístico, mas também suas dificuldades e conflitos disciplinares e institucionais ao longo dos últimos 40 anos.

\section{Palavras-chave}

Semiótica. Epistemologia. Teoria da Comunicação.

Complexidade.

Desde o lançamento de suas bases com Charles Sanders Peirce e Ferdinand de Saussure, no início do Século XX, e tendo como marco a difusão do estruturalismo a partir dos anos 1950, a Semiótica tem passado pelos mais diversos trânsitos - ou, para usarmos um termo caro à disciplina, pelas mais diversas traduções. Passagens entre continentes e 
perspectivas, desalojamentos institucionais entre campos como a Letras e a Comunicação, em uma dinâmica entre a invenção e a consolidação; uma história que é refletida na trajetória intelectual de Ione Maria Ghislene Bentz.

Com mestrado em Linguística em 1974, com orientação de Wilson Guarany, na Pontifícia Universidade Católica do Rio Grande do Sul (PUCRS), e doutorado em 1980, orientada por Izidoro Blikstein, na Universidade de São Paulo (USP), a formação da professora e pesquisadora está ligada à chegada dos estudos linguísticos e semióticos ao Brasil, e ao seu posterior desenvolvimento como um campo de pesquisa fértil aos problemas da comunicação e da cultura. Professora aposentada pela Universidade Federal do Rio Grande do Sul (UFRGS), com passagem pelo Programa de Pós-Graduação em Ciências da Comunicação da Universidade do Vale do Rio dos Sinos (Unisinos), hoje, ela atua como professora e pesquisadora junto à Pós-Graduação em Design da Unisinos. Conduzindo a experiência por esses espaços, o trabalho com a Semiótica e seu interesse pelos processos de significação e pelas linguagens sincréticas estão aí envolvidas.

Nessa entrevista, Bentz destaca pontos dessa trajetória, refletindo os avanços e as dificuldades na insurgência de novas propostas científicas. Pensa-se aqui sobre o lugar arisco da Semiótica, nessa sua tão intensa vida pela academia brasileira, de disputas tanto conceituais quanto institucionais. Em meio a isso, o que se destaca é sua potencialidade de fornecer uma matriz teórica epistemológica firme, ao mesmo tempo em que se apresenta como dispositivo para experimentações concretas e "laboratoriais".

O desenvolvimento da Semiótica no Brasil, pelos seus espaços e suas temporalidades, nos parece ligado com a sua própria trajetória intelectual e acadêmica. Como tu caracterizas a chegada desses estudos no país? Qual sua relação com esse primeiro momento?

Minha trajetória intelectual se confunde com minha atividade profissional. Quando cheguei à USP para o meu doutorado, em 1976, já vinha de uma experiência na Fundação de Ensino Superior do Vale do Taquari (hoje Univates [Universidade do Vale do Taquari]). Nesse período, as ideias estruturalistas chegavam por meio da Linguística, em um processo que começou no início dos anos 1950. Por questões várias, como a situação dos meios de comunicação e das relações acadêmicas internacionais, essas ideias já rodavam há um bocado de tempo em outros lugares, mas demoraram a circular no Brasil. Elas chegam ao Rio Grande do Sul por algumas mãos. A primeira é a do professor Wilson Guarany, que tinha feito doutorado na Sorbonne e, lá, havia descoberto a Linguística. Não "a" linguística, mas 
uma linguística. Não a de base mais dura, ligada à Fonologia e à Sintaxe, mas aquela que passamos a entender como Linguística/Semiótica. Mais ligada à Semântica, essa linguística conseguiu dar conta, ou responder a algo que o Gerativismo de Chomsky, que dominava a época, não conseguiu. Tudo ia bem até a gramaticalidade das frases, mas não se dava conta das metáforas ou das conotações etc. É com essa bagagem que o professor Guarany chega direto de Paris para PUCRS, com carta branca para montar um mestrado. Monta esse programa, como figura principal, com uma boa formação de linguística como ciência, que é como o Estruturalismo chegou aqui, através de Saussure, mas já aberto a todas influências que eu diria transdisciplinares. Estudávamos Kristeva, Barthes, Althusser, Derrida, entre outros intelectuais de ponta. Então, eu diria que nunca foi um mestrado ortodoxo, e essa formação foi surpreendente, porque nos colocou em uma roda mais ampliada e deu fôlego aos nossos questionamentos, pois cada aluno já partia para explorar uma dessas vertentes. Credito a isso a possibilidade de fazer uma semântica diferenciada, já que aparece, teoricamente, na proposição de uma Semiótica Greimasiana.

Esse processo seria anterior à passagem da Semiótica dos departamentos de Letras para os de Comunicação? Como ocorre esse trânsito?

Essa passagem é feita por essa visão ampliada da própria Linguística. Ela acabou ficando no seu lugar de origem, a Letras, institucionalmente, e acabou sendo vencida no embate entre uma ideia do estudo da língua pelos textos literários e as propostas de estudo por meio da cultura. 0 professor Joaquim Mattoso Câmara foi o primeiro a perceber que "existia algo, que não apenas a Literatura, a ser objeto de estudos das letras.". Um primeiro respiro que era tolerado, mas não necessariamente aceito, pois quando chega o Estruturalismo com uma proposta de ciência que vê a língua como um sistema e chega a formulações com uso de equações, começa uma briga, uma disputa teórica em que a compreensão de língua como cultura se vê atingida. Entrou pela Letras, mas gerou um conflito direto com o próprio conceito de Literatura. Um conceito sempre muito forte no Brasil, ao qual a visão científica se colocava como antípoda. A semiótica tratava os textos como quaisquer textos, não apenas os literários, e fazia perguntas que a Literatura não fazia. Ora, os cursos de Letras ficaram no aguardo enquanto a briga se dava entre os estruturalistas e os literatos. Esse desenvolvimento, ali dentro, foi sendo minado. Havia dificuldade, inclusive, da entrada nos currículos dessa Linguística que chegava para gerar controvérsias. 
Quem resolveu levar esses desafios, essas propostas, com mais força, foi a Comunicação. Muito em parte, também, por envolvimentos institucionais: como o caso da PUC/SP [Pontifícia Universidade Católica de São Paulo] que tinha sua pós-graduação em Semiótica e Comunicação e que realçou esse debate dizendo: "nós existimos e fazemos semiótica em várias áreas, inclusive na Comunicação". Foi influência, também, para criação do Mestrado em Semiótica da Unisinos. Nessa passagem, houve um esgarçamento positivo que gerou uma razoável tolerância à Semiótica. Mesmo assim, presentes nos currículos de graduação, as disciplinas foram desaparecendo, também, por falta de formação de professores para trabalhar com elas. Formalmente, não acho que haja um lugar consentido para a Semiótica hoje, nem na Comunicação.

Entretanto, não se deve balizar esse pensamento pela formação em universidades ou pela aceitação de programas e projetos de pesquisa. Também, percebo que as pessoas da minha geração não se dizem estruturalistas, mas tu identificas sua formação no jeito de pensar. Há uma forma do raciocinar que identifica o pensamento estrutural. Chegou, perturbou, se transformou e, transformando-se, os efeitos estão aí. Passou, mas esses anos [de] 1950, 1960 e 1970 não foram em vão.

Como tu avalias esses embates no campo da Comunicação? A que se deve essa perda de um "lugar consentido"?

Para os estruturalistas, não há diferença entre descrição e análise. Era análise crítica. O que se fazia a partir daí [era] descrever categorias, propor categorias, mostrar os movimentos relacionais e chegar a uma formulação que desse conta de uma classe de textos. Porém, a quem interessa uma estrutura algorítmica ou um resultado que dê conta de uma classe de textos, se o que interessa são interpretações socioculturais ou a vida dos textos pela sua leitura?

A Comunicação sempre se pautou por processos de ordem midiática e social, não se contentando com as respostas desses estudos sistêmicos. Reconhecia-se que a metodologia era rigorosa teoricamente, mas, para nós, a descrição já era a análise e, portanto, não precisaria haver uma interpretação: uma descrição que explicaria tal texto. Identificada a estrutura estruturante, não haveria resposta só para um texto, mas para todos os possíveis textos a serem gerados. Entretanto, isso foi cortado quase pela raíz. Dizia-se "não queremos estrutura de texto, isso é uma coisa muito dura". Não se sabia muito bem para o que aquilo serviria e se as perguntas que tinham seriam iluminadas por essas metodologias. 
Houve uma série de equívocos históricos, sobretudo naquilo que foi sendo apropriado de forma "leve" (trabalhos não rigorosamente científicos). Não pelo que estava sendo desenvolvido por pesquisadores de ponta, como os da USP ou da PUCSP, mas pela rápida popularização de um tipo de interpretação que parecia ser livre e subjetiva. A crítica acabou sendo pesada, levando à desconsideração de tudo que dali viesse. Assim, na apropriação da Semiótica, ela acabou sendo tratada como um lugar de livre interpretação, um lugar de pouco precisão conceitual. Um espaço de termos importantes como signo, por exemplo, que acabaram perdendo sua especificidade e [foram] usados como fala de senso comum. Nesse processo, a relevância de uma origem científica acabou se perdendo. Contrariamente, entretanto, proliferou e, repito, ainda está por aí.

A semiótica surge muito próxima dos movimentos de vanguarda não só no campo das artes, como também dos formalismos no cinema, por exemplo. No Brasil, depois dos anos 70 e 80, quando ela perde a proximidade com as vanguardas, em função de um movimento histórico em que o pensamento retrocede ao século XVIII com a volta do autor, o retorno de uma discussão da recepção que não passa por teorias da leitura como elaborada por Barthes. A Semiótica perdeu a guerra ou essa guerra ainda pode ser vencida?

Eu voltaria um pouco. Quando eu falo da literatura eu estenderia para as artes. Mesmo os irmãos [Augusto e Haroldo de] Campos e Décio Pignatari não estavam confortáveis com as consequências do modelo semiótico se não para a criação, mas para a análise.

\section{Haveria irmãos Campos sem modelo semiótico?}

Claro. Não depende disso. Os modelos não se confundem com a realidade; o desenho que fazemos dela tem várias fontes de inspiração, e em tempos de Modernismo, Concretismo, etc., processos estruturantes alcançaram alto potencial inspirador. As teorias não se confundem com ela, a realidade, [elas] a antecipam ou [a] sucedem, não importa, mas a significam de várias formas. Os modelos semióticos conseguiram dar compreensão, discernimento, organização e diferenciações caras à produção de arte. A arte sempre se produz, nunca é produzida. Talvez tenham faltado experimentações resultantes dos estruturalismos, dessa compreensão, dessa dinâmica com tão bons resultados tanto em artes, quanto em ciências. Não se fez, porque a preocupação maior era compreender aquilo que nunca foi fácil, a Semiótica nunca foi fácil de dominar. Talvez seja isso de que reclamo, 
mas não acho que haja qualquer atrelamento a nenhum modelo. As experimentações, sim, mais do que as ditas aplicações, podem produzir coisas fantásticas e inovadoras. As formas de experimentação, as experiências 'laboratoriais' talvez pudessem ter sido um ponto importante de aproximação entre a pesquisa em Comunicação que, se não é, deveria ser laboratorial. É isso, quem sabe o casamento entre esses dois campos de conhecimento não poderia ter sido mais harmonioso?

A sua carreira foi laboratorial? As suas experiências de gestão, por exemplo, não foram um laboratório de Semiótica?

Provocadora a questão. A minha formação em Linguística e Semiótica mudou meu paradigma. Nunca mais depois desses estudos, desde a cozinha até a praça, deixei de me organizar e organizar o entorno semioticamente. Para os que não entendem que o pensamento e a emoção caminham juntos, pensam: 'mas que coisa chata'. De modo nenhum. A gente pensa, sente, vive a partir de parâmetros, de percepções que estão conformes à nossa matriz cognitiva. Nesse sentido, minha vida tem sido um laboratório de Semiótica. A Semiótica não foi um casaco que vesti, foi uma pele que cobriu a minha primeira pele como uma máscara que não desgruda da pele original. Uma simbiose, um amálgama. Para qualquer coisa que eu olhe, pergunto: "no que isso é diferente daquilo? Essas diferenças são de que ordem?". É um bom vício. Quanto à experiência de gestão e do magistério, elas foram sempre pautadas por esse tipo de movimento, diríamos, cognitivo.

Parece que a semiótica assume para ti uma posição tripla: uma matriz epistemológica e ideológica e um dispositivo teórico experimental, também, calcado em uma função pragmática. Como entendes o funcionamento conjunto dessas três dimensões na pesquisa em Semiótica e na Comunicação em geral?

Tenho percebido que as Ciências Sociais fazem pesquisa aplicada. Descobri que o Design não faz pesquisa aplicada, faz produção e práticas que, em pesquisa avançada, devem ser compreendidas, faladas e ampliadas. Pensei que Comunicação também fizesse produção, mas quase toda a pós-graduação avançou, a partir de pesquisa bibliográfica, modelos e uso de teóricos, em direção à pesquisa aplicada. As habilitações, as antigas, pelo menos, ficaram de lado. Não pretendo fazer o contraponto com o pragmatismo, não é o caso, mas é inegável o poder das teorias de Foucault para tratar do jornalismo. Talvez se pudesse perguntar em que Foucault alterou o fazer jornalístico em Porto Alegre. Caberia uma pergunta deste tipo? 
Responderia ao pragmatismo de inspiração Peirceana, via Morris? O dispositivo teórico de inegável importância ganharia pertinência pragmática reconhecível? Como não ressaltar o fundamento epistemológico como identificador das bases teóricas? Sim, vejo essas matrizes, dimensões ou dispositivos interligados. Aliás, que bela discussão poderia ser feita a partir da compreensão operativa (o que não significa concreta) dos dispositivos!

Uma coisa reconhecemos: os problemas que temos como sociedade precisam ser antecipados, refletidos e pensados pela universidade (não só, mas especialmente). É seu compromisso. Não é apenas pegar uma teoria, conhecê-la bem, aplicá-la, trabalhar com categorias e chegar a conclusões, mas descobrir, criar, formular ou propor novos modos de conhecer ou de fazer. Perguntaria em relação à semiótica: ela tem, ou pode ter, vocação projetual? Que supostas novas relevâncias viriam deste compromisso de construção/reconstrução de uma sociedade problematizante/problematizada? Enfim, seria um desafio a ser respondido pelas dimensões anteriormente indicadas por uma pergunta. Aliás, o que problematizar ou o que fazer é o que não nos falta nestes tempos de Brasil.

A semiótica não seria, então, uma teoria meramente formalista no mau sentido, com muito pouco a dizer sobre os contextos políticos e sociais concretos que estamos imersos?

$\mathrm{Na}$ origem da semiótica, o que se desenhou foi uma formalização dos contos populares. Não apenas os russos, mas a estrutura dos contos populares como um todo. Hoje em dia, em tempos de indústria 4.0, essas sistematizações dariam um belíssimo aplicativo. A matéria dos aplicativos, as sistematizações, os softwares são concernentes às formalizações. Talvez essa pudesse ser uma nova chave de leitura para as propostas da Semiótica.

Há uma coisa que preciso dizer. Andei por vários terrenos: saí da Linguística, fui para Comunicação e agora estou no Design, mas sou apenas uma cabeça, um só campo: Semiótica. Eu opero por aí, e as contestações vêm das áreas nas quais a semiótica se acopla. Sou rigorosa quanto à precisão teórica e à coerência entre epistemologia e metodologia. Não considero a metodologia como um conjunto de técnicas ou ferramentas de pesquisa desligadas daquilo que se está investigando e da episteme, isto é, de um recorte de visão. Entretanto, se aquilo que estás investigando está organizado em corpus, o teu corpus pode acabar não se movendo. Quem sabe se absorvermos a ideia de exemplo e contraexemplo trazida por Noam Chomsky. Ele não trabalhava com um corpus fechado, mas com exemplos de fala que se contrapunham às frase-modelos que já haviam sido desenhados. Não acho que devamos abandonar a ideia de corpus, mas é preciso entendê-lo como uma plataforma de 
salto, a partir do qual, o tal salto, pode acontecer muita coisa diferente e instigante. Se te isolas na ideia do corpus como plataforma, ele se fecha e não se dinamiza.

Você se afirma como uma pessoa que passou por várias áreas, mas que tem um só campo, a Semiótica. Ao mesmo tempo, críticos afirmam que você abandonou a Semiótica. No que eles têm razão ou não?

Eles têm razão. Se eu mandasse um texto de Semiótica para uma revista específica da área, não receberiam. Não receberiam por causa da disciplina dos autores e da disciplina da execução. Entre o pessoal que se manteve mais rigoroso, há muito maior fidelidade a autores. Essa "matriz de pensamento", que para mim é importante, não é tão importante para os outros. Às vezes, sequer reconhecido e muitas vezes considerado displicência ou "ressignificações impuras". A matriz inclusive não é nem percebida pelos alunos. Quando é percebida, eles a usam. Acabo dando maior valor à matriz que gestou a Semiótica do que às teorias semióticas por ela gestadas. Permito-me reinterpretar com alguma ousadia pouco rigorosa, quem sabe por que o mundo se move e as coisas se transformam e, também, nós nos transformamos em nosso modo de ver o mundo. Reconheço não ser bom ficar sem 'tribo' e sem todas as boas inclusões dela decorrentes.

Dada essa trajetória, como tu entendes esse termo polêmico da interdisciplinaridade? A semiótica é interdisciplinar? Qual a validade desse termo?

Percebi que o que precisa ser revitalizado hoje em dia é o conceito de sistema, à luz de uma Teoria da Complexidade, proposta por Edgar Morin. A noção de sistema, assim proposta, demanda rever o conceito de sistema/ato e as clássicas dicotomias saussureanas. Reconheço relações de dependência entre os elementos de um sistema, mas pode haver ruído ou acaso que o altere, em previsões, portanto, ou sem recurso a um reconhecido sistema. Pensando na linha do contraexemplo, se alguém cutucar as minhas teses, em vez de suprimi-las para evitar a perturbação, vou agregar importantes conexões. Um acaso, um cacoete capaz de alterar o sistema. Pode ser que o uso de "tipo" que pode, quem sabe, funcionar como um prefixo que não sendo, aparece antes das palavras em português. Assim: "tipo mãe, tipo comi, tipo banana, tipo não vou etc". A língua é viva. São essas rupturas que criam as novidades. Obviamente, não sou contra o sistema/ato, mas sou a favor das potencialidades do sistema mais abertos e de uma complexidade que não seja entendida como "isso é complexo, isso não é complexo", mas como um olhar que contemple justamente 
essa complexidade e abertura dos sistemas. Pois, afinal, quem é complexo é o mundo, gente. Nesse sentido, é mais do que multi, inter ou qualquer coisa: é transdisciplinar. Escapa-se da discussão do que seja ou não inter, multi ou pluri-disciplinaridade. Aceita-se que o teu problema requer, invoca outras áreas para que mais se saiba sobre ele, ou para que mais tentativas de respostas sejam alcançadas. Que outras áreas tu precisarias invocar? Quais os ganhos? Como não esterilizar este potencial conceito pela visão de que pessoas de diferentes especialidades se devam reunir e aportar sua contribuição? Por que não reconhecer o valor da quebra da disciplinaridade, em vez de interpretá-la como 'coisa coletiva de pessoas que querem trocar'. Enfim, não sei bem, apenas intuo que pode ser muito bom e diferente.

\section{A Semiótica é um dispositivo metateórico?}

Sim, é um maravilhoso dispositivo metateórico, mas precisamos reconhecê-lo nos vários níveis de meta: linguagem-objeto e, então, meta linguagem/teoria, metameta (metodologia) ou metametameta (nível de epistemologia). Se não distinguirmos esses níveis de deslocamento vertical e interdependente, reduzimos o poder do termo, ou tiramos sua potencialidade maior. Às vezes, acho que sabemos bem o que fazer com esse tal dispositivo e acabamos procurando outras companhias como, por exemplo, a psicanálise, combinações horizontais e não de níveis, embora, nos preocupemos com coerências do tipo como Lacan propõe o psiquismo como linguagem, olha bem coerente (nem tanto nos desdobramentos) com a proposta da Linguística/Semiótica.

Quais seriam as companhias possíveis e as impossíveis da Semiótica na contemporaneidade e como analisas a relação com a fenomenologia?

O que é o contemporâneo? Não sei o que é isso. Sofremos uma crítica de matriz e vivemos um imperialismo do objeto com uma ideia bastante datada de deixar o objeto falar. É importante que se diga que a academia tem um compromisso com a metalinguagem, com o rigor conceitual e com a formulação de interpretações relevantes, a partir de teoria bem constituída. Mas, nesse meio, deve haver alguma desordem, sem o que haveria pouco a descobrir. Nesse ponto, é preciso que se diga que as teorias semióticas são muito bem constituídas.

Estruturalismo e pragmatismo tiveram uma raiz comum, mas depois houve uma dicotomização em duas vertentes que se dizem incompatíveis. São epistemes que mantém, de um modo ou outro, seu prestígio científico. Poderia tentar explicar que a ruptura prende- 
se ao fato de que a matriz antes de ser semiótica é linguageira e, aí, aparece a noção de representação. Já houve tentativas sem sucesso, digo eu, de abandonar a noção de representação. Quando o pragmático olha para a realidade e diz "é isso" e pronto, ele identifica o significado, mas não opera com a representação pela linguagem. Modo raso de ver, talvez? E a fenomenologia, e o modo com a ciência hegemônica a vê, como não científica, como não rigorosa?

Fenomenologias bem reconhecidas - Heidegger, Merleau-Ponty etc. - reconhecem tipos diferenciados de cognição e propõem diferentes metodologias. Parecem inventivas, sempre capazes de uma descoberta não prevista pelas regularidades sistêmicas ou pelas metodologias descritivas ou prescritivas. As posições fenomenológicas não favoreceriam as práticas abdutivas? Em determinado momento, não fariam renascer percepções excluídas pelo rigor das ciências 'duras'? A ciência é irmã gêmea da arte, da inventividade. 0 método é importante para percorrer os caminhos, mas não pode soterrar ou anular a imaginação e a descoberta. Pela possibilidade que a fenomenologia tem de trabalhar com hipóteses absurdas, não apenas com consensos de que derivam hipóteses, talvez ela abra possibilidades. 0 insight, a intuição de ordem sensitiva, não pode ser perdida. Abordamos o problema a partir de uma série de questões que são da ordem do pensamento semiótico, mas não podemos trabalhar com uma percepção que já esteja previamente racionalizada. Como escapar desta armadilha? Onde fica a imaginação na ciência?

Há espaço para isso na pesquisa da Comunicação, marcada por uma lógica abdutiva, por exemplo?

Não há, em princípio, interdições: há escolhas e ousadias. 0 pensamento abdutivo está na origem e antecede qualquer organização de pesquisa, mas também é possível pensar adiante a partir de hipóteses de futuros inventadas. Por exemplo, é possível pensar a partir da negação de todo de qualquer saber acumulado sobre documentários como narrativas. Tudo absolutamente negado. Logo a pergunta: 0 que aconteceria? O que se descobriria? Que nova ordem de formulações seriam feitas? Que novos objetos-documentário viriam a ser criados? Boas perguntas... Não interessa a ninguém se perguntar sobre isso? Nós temos mantido uma trilha de pesquisa de conformidade a moldes e tradições que acaba tendo pouca inventividade. Estarei sendo demasiado severa? 
Seria algo como perguntar "e se", em vez de buscar as melhores hipóteses para explicar um efeito?

Seria estimulante pensar em situações como "e se algo". Essa abertura poderia orientar trabalhos com metodologias diferenciadas. Não devemos estar completamente configurados racionalmente. Não existe isso, pelo menos não acho bom. A psicologia não conseguiu separar o sensível do racional, mas continuamos trabalhando com uma racionalidade que se sobrepõe às sensações. Ela deve se sobrepor na ciência e ocupar o espaço da imaginação; deve ter um lugar precedente na configuração de um projeto de pesquisa.

Há pessoas experimentando em algum lugar. Provavelmente, são estes trabalhos que estão em número minoritário nas estatísticas. 0 lugar para esta inventividade é a fase de pré-formatação do projeto. Se existe este espaço inventivo, o desenvolvimento do projeto vai respeitá-lo. 0 problema é que essa discussão de inventividade está muito distante da ciência e torna-se necessário inventar um lugar para a descoberta. A academia exige projetos perfeitos em que a pessoa precisa saber antecipadamente aonde quer chegar e acredita que o como fazer dará respostas. Esse é o formato que atende à exigência da academia. $\mathrm{O}$ formalismo negado à origem estrutural domina toda a estrutura universitária.

Como analisa a semiótica da perspectiva do modelo e da necessidade de ser experimental?

Desloquei a Semiótica para uma forma de organização do pensamento e de percepção do mundo. Usar modelos é outra opção. Usar tudo isso para fomentar ou propor experimentações é apenas outra funcionalidade. Acredito que na experimentação a Semiótica se reinvente. Fica um convite: vamos, Comunicação e Design criar um laboratório que teste o potencial da Semiótica para propor sistemas, processos, produtos ou quaisquer outros artefatos?

\section{Agradecimentos}

Agradecemos a presença de Alexandre Rocha da Silva, Bruno Leites e Marcelo Bergamin Conter pela participação na entrevista. 


\title{
Reinventing Semiotics: an interview with lone Bentz
}

\begin{abstract}
With a Master's degree in Linguistics from 1974 (PUCRS) and a PhD from 1980 (Universidade de São Paulo), Ione Betnz's formation is strictly connected with the arrival of the linguistic and semiotic studies in Brazil and also with its further development as a fertile research field for communication and cultural problems. Emeritus professor from Universidade Federal do Rio Grande do Sul and a part of the Postgraduate Program of Communication Sciences at Universidade do Vale do Rio dos Sinos, nowadays lone works as professor and researcher in the Postgraduate Program of Design at Universidade do Vale do Rio dos Sinos. In this interview, lone discusses the particularities of Semiotics as a research field in the country, highlighting its potentialities as an epistemic and heuristic instrument, but also its disciplinary and institutional difficulties for the last 40 years.
\end{abstract}

\section{Keywords}

Semiotics. Epistemology. Communication Theory. Complexity.

Recebido em 11/04/2018

Aceito em 12/04/2018 